Article

\title{
Characterizing Geological Heterogeneities for Geothermal Purposes through Combined Geophysical Prospecting Methods
}

\author{
Cristina Sáez Blázquez *D, Pedro Carrasco García, Ignacio Martín Nieto, \\ Miguel Ángel Maté-González ${ }^{\mathbb{D}}$, Arturo Farfán Martín and Diego González-Aguilera \\ Department of Cartographic and Land Engineering, University of Salamanca, Higher Polytechnic School \\ of Avila, Hornos Caleros 50, 05003 Avila, Spain; retep81@usal.es (P.C.G.); nachomartin@usal.es (I.M.N.); \\ mategonzalez@usal.es (M.Á.M.-G.); afarfan@usal.es (A.F.M.); daguilera@usal.es (D.G.-A.) \\ * Correspondence: u107596@usal.es; Tel.: +34-675-536-991
}

Received: 22 May 2020; Accepted: 15 June 2020; Published: 17 June 2020

\begin{abstract}
Geothermal energy is becoming essential to deal with the catastrophic effect of climate change. Although the totality of the Earth's crust allows the exploitation of shallow geothermal resources, it is important to identify those areas with higher thermal possibilities. In this sense, geophysical prospecting plays a vital role in the recognition and estimation of potential geothermal resources. This research evaluates the geothermal conditions of a certain area located in the center of Spain. The evaluation is mainly based on geological and geophysical studies and, in particular, the Time Domain Electromagnetic Method and the Electrical Resistivity Tomography. Once we analyzed the geology and the historical thermal evidence near the study area, our geophysical results were used to define the geothermal possibilities from a double perspective. In relation to anomalous heat gradient, the identification of a fault and the contact with impermeable granitic materials at the depth of $180 \mathrm{~m}$ denotes a potential location for the extraction of groundwater. Regarding the common ground-source heat-pump uses, the analysis has allowed the determination of the most appropriate area for the location of the geothermal well field. Finally, the importance of accurately defining the position of the drillings was confirmed by using software GES-CAL.
\end{abstract}

Keywords: geothermal energy; geophysical prospecting; time domain electromagnetic method; electrical resistivity tomography; potential well field location; GES-CAL software

\section{Introduction}

The fight against climate change and its catastrophic effects is one of the main challenges that currently enrolls the whole world. Efforts are therefore focused on the exploration of renewable and clean energy sources that contribute to the gradual transition and reduction of fossil energies. Within the broad group of environmentally friendly resources, geothermal energy constitutes a versatile and excellent solution for electricity generation and other direct uses. The origin of the Earth's thermal energy is linked to the internal structure of the planet and the physical processes occurring there. The existence of this heat has been proved through the rocks' temperature, which increases with depth (gradient commonly averages $3{ }^{\circ} \mathrm{C} / 100 \mathrm{~m}$ of depth). However, gradients above the average can be found in areas with particular geological conditions. Armstead [1] divided the Earth's crust into non-thermal and thermal areas, considering that the last ones are characterized by temperature gradients greater than $40^{\circ} \mathrm{C} / \mathrm{km}$ depth. Focusing on very low-enthalpy geothermal resources, they can be practically found at any point of the crust, thanks to the constant ground temperature from depths of $8-10 \mathrm{~m}$. In these systems, heat can be extracted for heating and cooling applications, using 
geothermal heat pumps. From a certain depth, the ground can store the heat even seasonally, so that ground temperature is almost constant throughout the year. Within the common exploitation of these resources, some areas, with specific geological and stratigraphic conditions, are especially appropriate for the implementation of these geothermal systems.

The identification of potential geothermal areas is, nowadays, a challenging and costly task. The principal geological parameters of a geothermal reservoir to be defined are the tectonic structures (faults), permeability, lithology, temperature, and stress field. The most accurate way of determining the above factors is by in situ measurements in a borehole [2], which are frequently discarded because of technical and/or economic reasons. In this way, it is required the implementation of alternative solutions that allow an estimation of the geothermal potential. Fortunately, some of the mentioned parameters can be estimated from the surface, mainly by the application of geophysical methods. These techniques represent a primary tool for investigating the surface and are applicable to a wide range of issues. The principal application of geophysics is in prospecting for natural resources, but it is also used in geological surveying, in engineering, or archaeological-site investigations. Since these methods allow interpreting the ground stratigraphic and structural details at scales from tens to thousands of meters, they constitute a useful tool in hydrogeological and geothermal prospecting $[3,4]$. There are numerous methods within the term geophysics: Seismic, magnetic, gravimetric, thermal, or electric and electromagnetic techniques are some of the major geophysical methods used for geothermal exploration. Each one of these procedures presents a series of assets and limitations that must be analyzed before their selection $[5,6]$.

Numerous studies have addressed the geothermal prospecting from the application of geophysics [7]. The most widespread methods are the seismic, the electric, and the magnetic ones [8-15], but many others can be found in the current literature. As an example of the large geophysical implementation with geothermal purposes, the following published research is worth highlighting. Abubakar et al. [16] used improved remote sensing techniques to identify hydrothermal alterations in the Yankari Park (Nigeria). Arzate et al. [17] deduced the geothermal field model of Los Humeros (Mexico) from the use of magneto-telluric soundings. Along these lines, Long et al. [18] and Volpi et al. [19] applied similar methods to thermally define a certain area of Oregon and Italy, respectively. Hermans et al. [20] analyzed the shallow geothermal possibilities of a sandy aquifer by using electric resistivity tomography. As can be deduced from the above, geophysics has been deeply implemented in the geothermal context. However, most of the existing works are mainly focused on analyzing anomalous geothermal possibilities, without defining the final and real uses that a certain area may have as ground-source heat-pump system. This reason, together with the fact that there is an alarming lack of geothermal systems in the area considered here, has contributed to the development of this work. Thus, this research is not exclusively focused on studying the anomalous geothermal resources; it also addresses the importance of using geophysics, although low-enthalpy uses are expected.

This research firstly aims to determine the lithological composition of the ground materials by using two different geophysical prospecting techniques. From this information, the possible ground water geothermal use is evaluated, to finally define the most suitable area (within a certain perimeter) for exploration of future geothermal applications. Considering the particular characteristics of the area under study, these applications are limited to low-enthalpy geothermal uses (trough heat-pump systems), but the possibility of finding a promising thermal anomaly in the form of a hot spring could also be analyzable. Within the large number of geophysical techniques, this work includes the Time Domain Electromagnetic Method (TDEM) and the Electrical Resistivity Tomography (ERT). Beyond the analysis of anomalous geothermal activity, results of this work are also used to determine the exact location of the well field as part of a ground-source heat-pump system. Furthermore, a specific geothermal software is used to highlight the importance of an accurate well-field design. The following subsections accordingly describe the geological composition of the study area, the fundamentals of the geophysical methods implemented in the work, and the results obtained from them. Finally, discussion and conclusion sections establish the possible geothermal applications in the mentioned area. 


\section{Materials and Methods}

The principal objective of this section was to determine the characteristics of the study area, both from a geological and a thermal point of view. After this preliminary analysis, the geophysical methods implemented in this work are thoroughly described.

\subsection{Characterization of the Area under Study}

The area evaluated in this work is located in the province of Segovia, at the center of Spain. As shown in Figure 1, it is geologically constituted by mainly tertiary age materials in the Duero Basin. The most significant lithological units are described below.

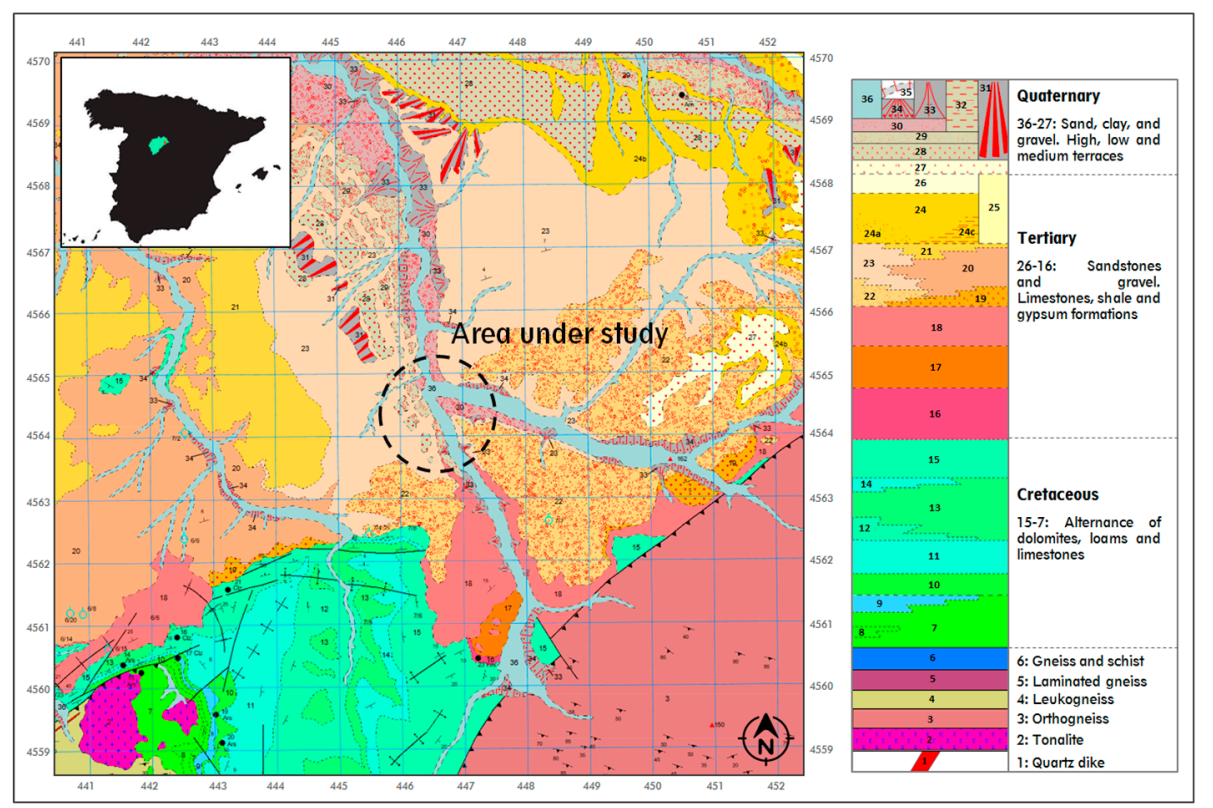

Figure 1. Geological composition of the area under study [21].

\subsubsection{Tertiary}

It is predominantly characterized by an alternation of clays, silts, sand, and sandstones. Sands are mineralogical constituted by quartz, feldspars, and micas, but also by igneous and metamorphic fragments (shales and granites). Sands are organized as sedimentary sections of lenticular and tabular geometry of variable thicknesses, with great variability in the vertical and horizontal layout. Clays and silts are included in the sand levels, behaving as isolation, to a greater or lesser degree, depending on the location.

Since it is a continental basin, in which the river sedimentation plays an important role, sands are arranged in lenticular layers with poor level of lateral continuity. Sections are distinguished by the frequency of the sandy layers and their permeability, but mainly by the permeability of the global matrix. Lenticular layers of sands and gravels encompassed in a semipermeable matrix behave as a large, heterogeneous, and anisotropic aquifer (confined or semi-confined, according to the different areas).

\subsubsection{Calcareous Mesozoic}

After the Tertiary, the area considered here is constituted by an alternation of dolomites, limestones, marls, and sandstones. Only the dolomitic and limestone-dolomitic sections of the Upper Cretaceous create aquifers of certain importance. The remaining areas are principally constituted by low-permeability materials. 


\subsubsection{Paleozoic}

Gneisses and granites, considered as impermeable, are expected in those low deep areas with high levels of erosion and fragmentation.

Once we analyzed the prevailing geology, it was also required to evaluate the evidence of existing thermal waters in the area of study. The Geological and Mining Institute of Spain [22] allows consulting the Spanish mineral and thermal waters, areas with proven evidence of thermal water, bottling plants, or officially declared waters. In Figure 2, it is possible to observe the different mineral and thermal waters close to the area under study.

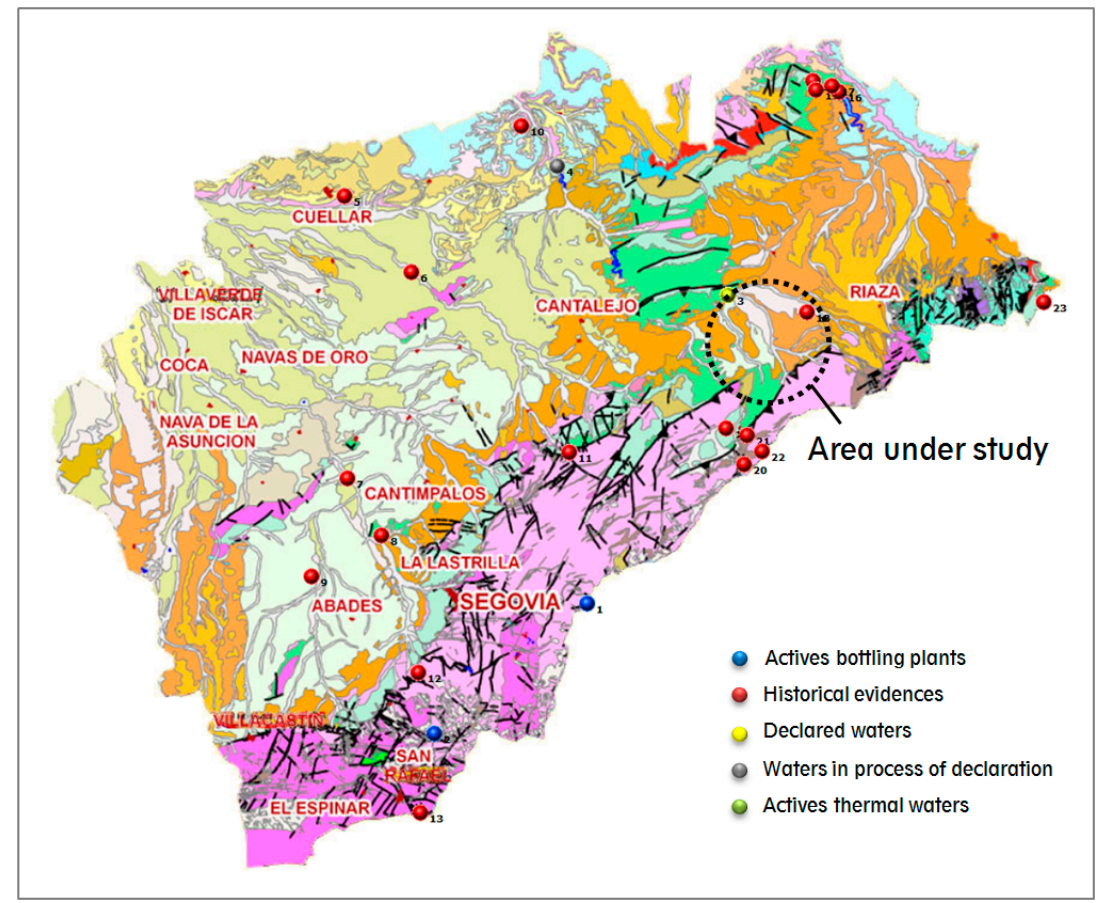

Figure 2. Thermal and mineral waters in Segovia, the Spanish province where the research is focused [22].

As can be graphically seen in Figure 2, there are several historical evidences near the studied area but also declared water. More information about these waters is presented in Table 1.

Table 1. Description of the water evidences close to the study area.

\begin{tabular}{cc}
\hline Classification & Description \\
\hline 18-Historical evidence & $180 \mathrm{~m}$ deep spring water drilling \\
& $\begin{array}{c}\text { Lithology: clays, sands, and gravels } \\
\text { Water temperature: } 14.7^{\circ} \mathrm{C}\end{array}$ \\
\hline 3-Declared water & Natural spring \\
& Lithology: Cretaceous limestones \\
& Water temperature: $20.8^{\circ} \mathrm{C}$ \\
\hline 20-Historical evidence & Unavailable additional information \\
\hline 21-Historical evidence & Natural spring \\
& Lithology: carbonated Cretaceous \\
& Water temperature: $11.7^{\circ} \mathrm{C}$ \\
\hline 22-Historical evidence & Unavailable additional information \\
\hline 23-Historical evidence & Unavailable additional information \\
\hline
\end{tabular}


From all of these data, it is especially remarkable the declared water number 3 , in which an anomalous thermal gradient (of above $20^{\circ} \mathrm{C}$ ) was found. The proximity of these evidences to the studied area and the geological similarity among them mean an important starting point to justify the geophysical prospecting tests performed at later stages.

\subsection{Geophysical Prospecting}

Before addressing how the field tests were carried out in the area considered here, it is important to briefly describe the fundamentals of the geophysical methods selected in this work.

\subsubsection{TDEM}

At the beginning of the 1980s, the Time Domain Electromagnetic Method emerged as a very relevant innovation in the geophysical field. The subsequent application of this method in numerous works has allowed us to accumulate a remarkable experience in different hydrological and mining research, underground environmental pollution, archaeology, or in the location of structures and complex subsurface anomalies [23-25]. As this is a widespread method already presented in a large number of published research studies, only a brief description is provided below.

TDEM is a geophysical exploration technique used to measure the electrical resistivity or conductivity of the subsoil. The common array consists of a transmitter unit connected to a loop that receives and sends the signal to a receiver unit. By injecting a constant current into the transmitter loop, a stable primary magnetic field is generated in the ground. When this current is instantly stopped (also stopping the existing magnetic field), an electromagnetic induction of electrical currents is produced in the subsoil because of the Faraday's Law. These currents pass through closed paths in the ground and migrate in depth and laterally, while their intensity decreases with time, also generating a decreasing transient secondary magnetic field on the surface. This secondary field induces a time-varying voltage at the receiver. The way in which the voltage drops contains the information about the ground resistivity, since the magnitude and distribution of the induced currents depend on this property. In this context, short-time voltages provide information about the shallow resistivity, while the long-time voltages are linked to deeper resistivities. The principal phases explained above are synthesized in Figure 3.

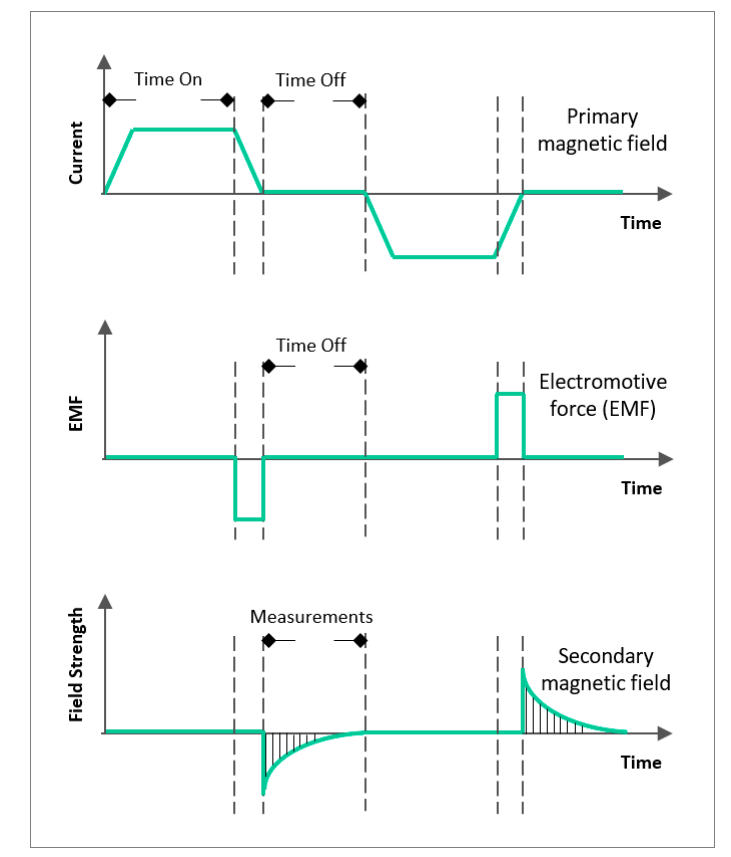

Figure 3. Time diagram in which the measurements are made by the receiver. 
The advantage of TDEM regarding other electrical and electromagnetic methods is its low sensitivity to the separation between transmitter $(T)$ and receiver $(R)$. In this way, TDEM is the only electrical method that can be applied with a separation $T / R$ lower than the depth of the structure that pretends to be found. This fact allows for the improvement of the lateral resolution of the method. However, longer distances are required for deeper prospecting to deal with noise effects [26].

In any case, the depth of prospecting in TDEM is determined, not by the T/R separation, but by the time, since the transmitter stops emitting at the associated magnetic moment. For greater depths, it is therefore necessary to collect the signal at later stages. It is obvious that, with short times, currents are concentrated in the superficial layers. The first electromotive force (EMF) measurements will be consequently more sensitive to the resistivity of the upper layers. As time passes, the current intensity reaches greater depths, and the measured EMF is more influenced by these depths. Furthermore, the current density decreases in the upper layers so that the electrical resistivity of these layers has low influence on the EMF measured over long periods of time. This fact contributes to eliminate the effect of near-surface resistivity variations, commonly the reason of losing quality in the final data obtained by other electrical prospecting methods.

In relation to the TDEM data processing, EMF, measured as a function of time, is converted into apparent resistivity. This resistivity is then introduced in an inversion tool which calculates the stratification of apparent conductivities by using the Spiker algorithm (adjusting in the best possible way to the curve of observed apparent resistivities). Specifications of the TDEM device can be found at Appendix A, Figure A1.

\subsubsection{ERT}

Two-dimensional electrical resistivity tomography is a technique widely used for the characterization of the subsoil with multiple purposes and applications. In general, its aim is the location of subsurface complex structures and anomalies (both geological and anthropic) [27-30].

ERT consists of measuring the apparent resistivity of the ground by using a tetra-electrode device with a constant separation " $a$ " among electrodes. Distances between the couples of electrodes (transmitter-receiver) are then varied by multiples of a value " $n$ ". The basis of this method is injecting a constant current in the ground through the transmitter electrodes and measuring the potential difference between the receiver ones. The final result is an apparent resistivity section for several levels in depth " $n$ ". Data are subsequently processed by inversion mathematical algorithms. The inversion results in real depths and resistivities image that must be verified with the geological information, existing drillings, or geochemical or hydrological data. Through the results interpretation, a final diagnosis is obtained.

With the purpose of finally converting the distribution of the ground real resistivity into a geological structure, it is necessary to know and consider the typical resistivities for the different subsoil materials and the geology in the area of study [31-33].

Data processing of this research was performed in the inversion software RES2DINV. This tool is based on the least square's inversion technique with smoothing restriction, using Equation (1) [34-36].

$$
\begin{aligned}
& \left(J^{T} J+u F\right) d=J^{T} g \\
& F=f_{x} f_{x}{ }^{T}+f_{z} f_{z}{ }^{T}
\end{aligned}
$$

where $f_{x}=$ horizontal flattening filter; $f_{z}=$ vertical flattening filter; $J=$ partial derivates matrix; $J^{T}=\mathrm{J}$ transposed matrix; $u=$ softening factor; $d=$ disturbance model vector; and $g=$ discrepancy vector.

The 2D model implemented in this software divides the ground into a certain number of rectangular blocks. The objective is to determine the real resistivity of the rectangular blocks that would produce a pseudo-section of apparent resistivities as the ones measured in the field. Depending on the device used, the thickness of the first layer of blocks is variable ( 0.5 times the space among electrodes for Wenner and Schlumberger devices, 0.9 for the Pole-Pole, 0.3 for the Dipole-Dipole, or 0.6 for the 
Pole-Dipole). For the next deeper layer, the thickness will be increased in $10 \%$ to $25 \%$. Layers' depths can also be defined by the user. Specifications of the ERT device can be found at Appendix A, Figure A2.

\subsection{Field Work}

Regarding TDEM prospecting, ten tests were carried out in the perimeter of the area under study. All TDEMs were performed with a loop of $200 \times 200 \mathrm{~m}$ and implemented the coincident loop mode. The UTM coordinates of each TDEM is included in Table 2. Coordinates were obtained by using a GNSS (Global Navigation Satellite System) with an accuracy of $\pm 1 \mathrm{~cm}$ in planimetry. The reference system is the European Terrestrial Reference System 1989 (ETRS 89). The use of this system allows a perfect geo-location of the tests.

Table 2. UTM coordinates (time zone 30T) of each TDEM made in the area considered in this research.

\begin{tabular}{ccc}
\hline Test & $\mathbf{X}$ & $\mathbf{Y}$ \\
\hline TDEM-1 & 447,377 & $4,564,903$ \\
TDEM-2 & 447,289 & $4,564,603$ \\
TDEM-3 & 447,165 & $4,564,251$ \\
TDEM-4 & 446,949 & $4,564,139$ \\
TDEM-5 & 446,641 & $4,563,959$ \\
TDEM-6 & 446,353 & $4,563,763$ \\
TDEM-7 & 446,277 & $4,563,283$ \\
TDEM-8 & 446,637 & $4,562,667$ \\
TDEM-9 & 446,257 & $4,564,295$ \\
TDEM-10 & 448,085 & $4,562,743$ \\
\hline
\end{tabular}

For each TDEM, at least one register was made, using a staking of 1000 repetitions of the measurement for each channel. In each of the mentioned registers, 73 channels were measured. However, for the size of the loop, from channels 35 to 40, measurements were affected by the background noise, higher than the signal to be measured. First channels were also affected by the slope, so that first and last channels were discarded in the corresponding data processing. Figure 4 shows the TDEM equipment during the tests in the area under study.

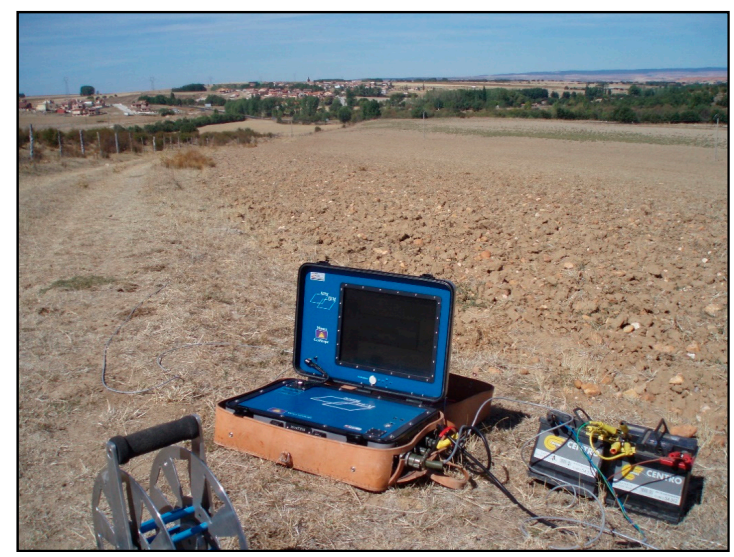

Figure 4. TDEM equipment in the area under study.

Relative to the implementation of ERT, $725 \mathrm{~m}$ was measured in a profile distributed in the area under study. Pole-Dipole and Schlumberger devices were used in this prospecting. Pole-Dipole was selected considering the great depth of penetration (around $250 \mathrm{~m}$ in this case) and the high resolution. The separation among electrodes was of $25 \mathrm{~m}$. The beginning and ending (in UTM coordinates) of the ERT profile are shown in Table 3. These coordinates were obtained with the previously mentioned GNSS system. 
Table 3. UTM coordinates (time zone 30T) of each TDEM made in the area considered in this research.

\begin{tabular}{ccc}
\hline Profile 1 & X & Y \\
\hline Starting point & 446,708 & $4,564,016$ \\
Ending point & 447,334 & $4,564,353$ \\
\hline
\end{tabular}

In Figure 5, it is possible to observe the location of the TDEM and ERT prospecting in the area considered in this research.

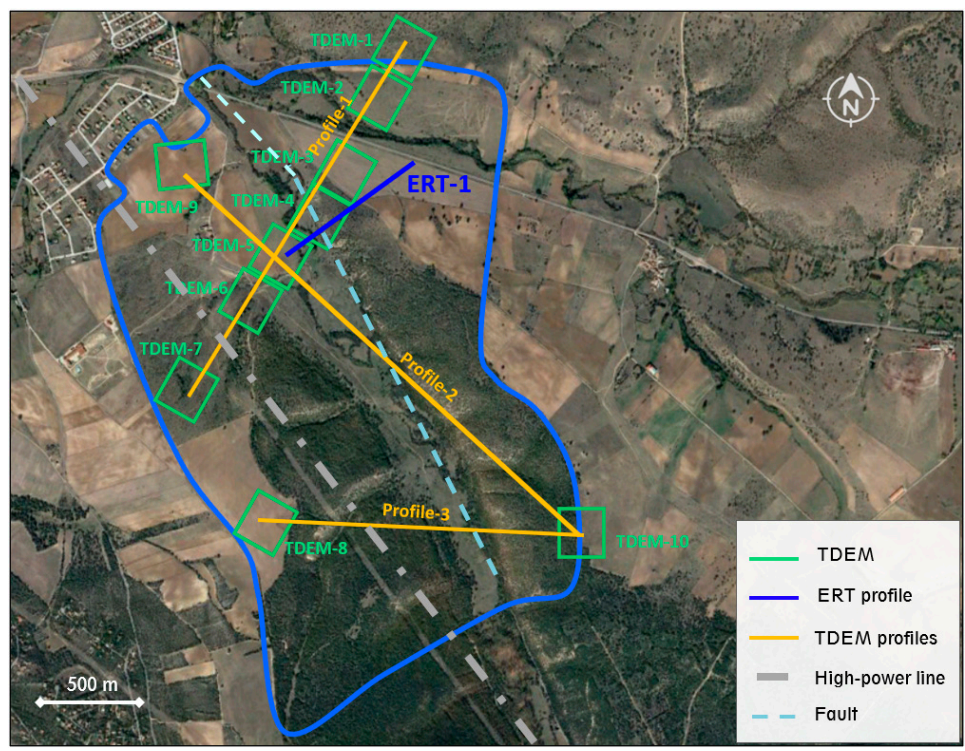

Figure 5. Location of the geophysical tests (TDEM and ERT) performed in the area under study.

\section{Results}

Results derived from the 2D interpretation of the electromagnetic tests (TDEM) are shown in Figures 6-8. Sections of iso-resistivities curves reflect the spatial variation (2D) of the apparent resistivity in each TDEM profile. This variation is mainly due to lithological alterations corresponding to different levels of ground materials. However, it is also possible to find sections with different resistivities in the same lithological formation because of other external factors.

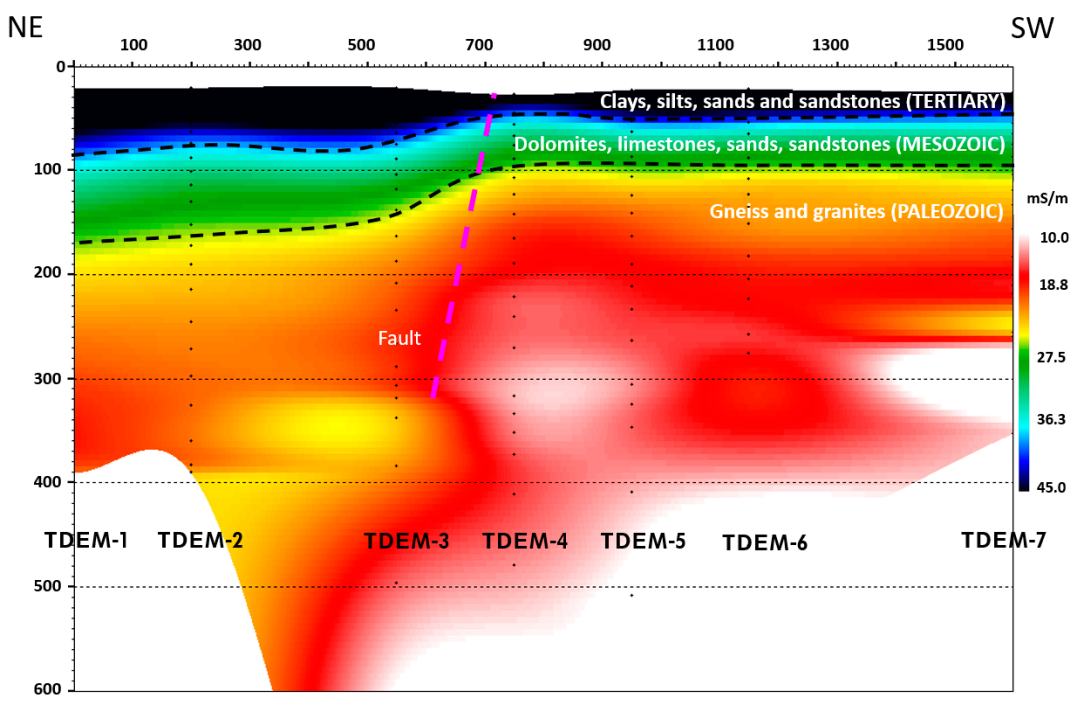

Figure 6. Two-dimensional interpretation of electromagnetic prospecting, TDEM-profile 1. 


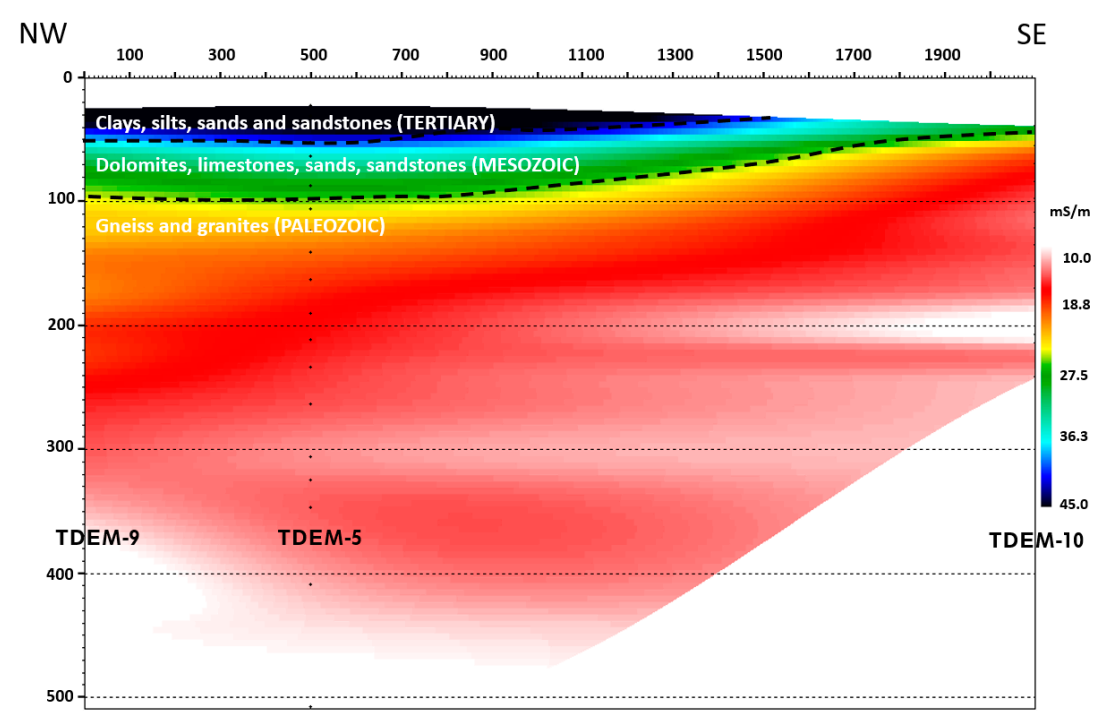

Figure 7. Two-dimensional interpretation of electromagnetic prospecting, TDEM-profile 2.

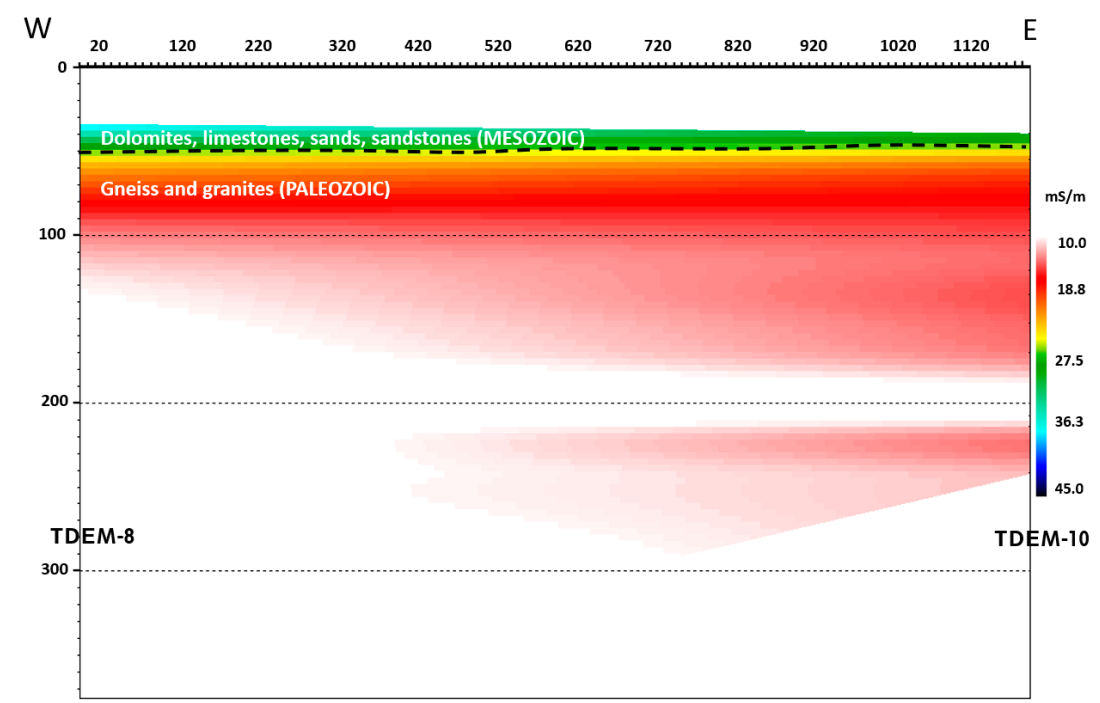

Figure 8. Two-dimensional interpretation of electromagnetic prospecting, TDEM-profile 3.

Field results from ERT prospecting were processed with the aim of building 2D geo-electric sections (sections of resistivities and depths) for the different profiles. The variations of resistivities derive from lithological changes in the lateral direction and in depth. The ERT section of this work is represented in Figure 9.

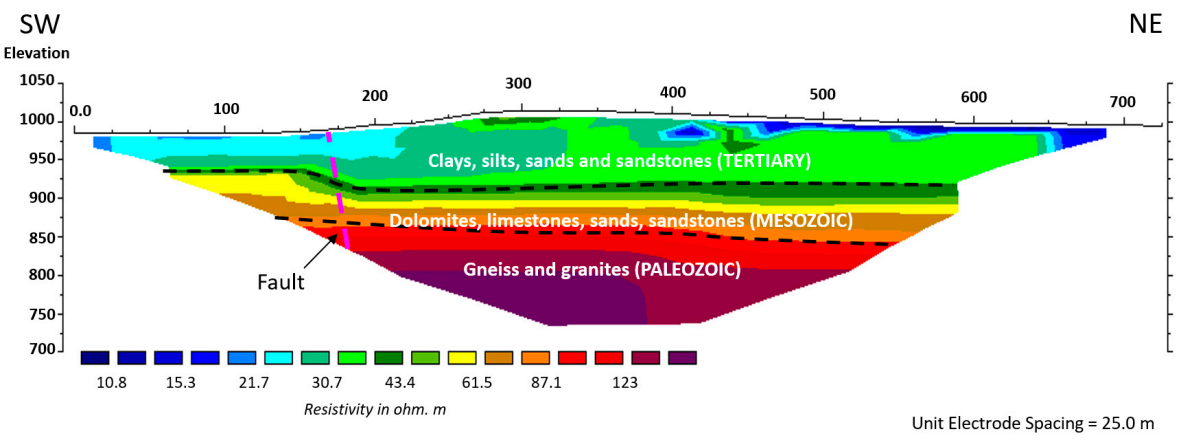

Figure 9. Two-dimensional resistivity section from the ERT profile in the area under study. 
In Figures 6-9, above, the different geo-electric unities and the materials associated are represented. Geophysical data (resistivities) are converted into lithological information based on a series of correlation criteria that consider previous studies in the area (geology) and previous fieldwork in similar geological scenarios. The analysis of the geophysical prospecting brings to light the existence of three main unities: Tertiary (clays, silts, sands, and sandstones), Mesozoic (dolomites, limestones, sands, and sandstones), and Paleozoic (gneisses and granites). Results also evince the presence of a fault associated to the Duratón River.

The determination of each of the geological formations is mainly based on knowing the geology in the area (already described in Section 2.1) and the standard values of the resistivity/conductivity typically associated to each material. In this way, standard resistivity or conductivity values (obtained from different official databases) are the basis to connect each layer (with a specific resistivity) with a geological formation. However, beyond this information, the experience of the geophysicist is essential to accurately define materials of the ground. This technician is finally the key factor to achieve a reliable interpretation of the subsoil.

\section{Discussion}

The area under study is located in the Duero Basin, one of the stables areas of the Earth's crust characterized by normal geothermal gradient $\left(3^{\circ} \mathrm{C} / 100 \mathrm{~m}\right)$. In this way, the geothermal possibilities are focused on the existence, at the appropriate depth, of permeable materials capable of containing and allowing the movement of fluids to extract the heat from the rock. Based on previous studies from the Geological and Mining Institute of Spain (IGME), the temperatures of the aquifers in the detrital Tertiary of the Duero Basin (area of this research) in the depth of 0-200 $\mathrm{m}$ vary in the range of $12-20^{\circ} \mathrm{C}$.

\subsection{Anomalous Geothermal Possibilities}

As mentioned above, the possibility of achieving an especial use of geothermal resources (beyond the normal use as ground-source heat-pump systems) in the area of study is limited to the existence of particular geological formations. The geophysical tests performed here reveal that, around the depth of $180 \mathrm{~m}$, it is possible to find the contact with the impermeable granitic materials from the Paleozoic. In order to estimate the temperature in the aforementioned level, it is convenient to consider the average annual temperature in the area under study. This information can be found in Figure A3, from Appendix B. As Figure A3 shows, the temperature in the area of this research is around $11.7^{\circ} \mathrm{C}$ for the period considered. From this value, and considering the normal geothermal gradient, the temperate at the depth of $180 \mathrm{~m}$ would be of about $17.1^{\circ} \mathrm{C}$. This temperature could be higher, since the contact is constituted by granitic materials (characterized by high thermal conductivities) that could provide a higher amount of heat to the groundwater.

From the depth of $180 \mathrm{~m}$, it would be interesting (from the geothermal point of view) to perform a drilling in the location of the fault represented in Figures 6 and 9. In this position, it could be possible to find meteorized permeable granitic materials accumulating groundwaters. Additionally, it might be the case that deeper water flows reach the fault with higher temperatures. It should also be remembered the documented natural spring (Table 1) in the vicinity of the study area with temperatures of above $20^{\circ} \mathrm{C}$ and placed in similar lithology. In the case that geological formations in depth are permeable or fractured, and if there is groundwater circulation, this water is capable of capturing the heat from the rocks and reaching the surface through crevices or faults. Once in the surface, it could lead to the generation of thermal waters or geysers (depending on the geothermal gradient, the groundwater temperature). In this sense, the existence of a fault in the area under study is not in itself an indication of anomalous geothermal activity, but if this was the case, the fault constitutes the way of using the geothermal resource in the surface.

Based on the results obtained throughout this research, Figure 10, below, shows the location of the area recommended for the collection of groundwater, with high possibilities of reaching an anomalous 
thermal gradient. Figure 10 also includes the exact position of the drilling to carry out the exploitation of the geothermal resource.

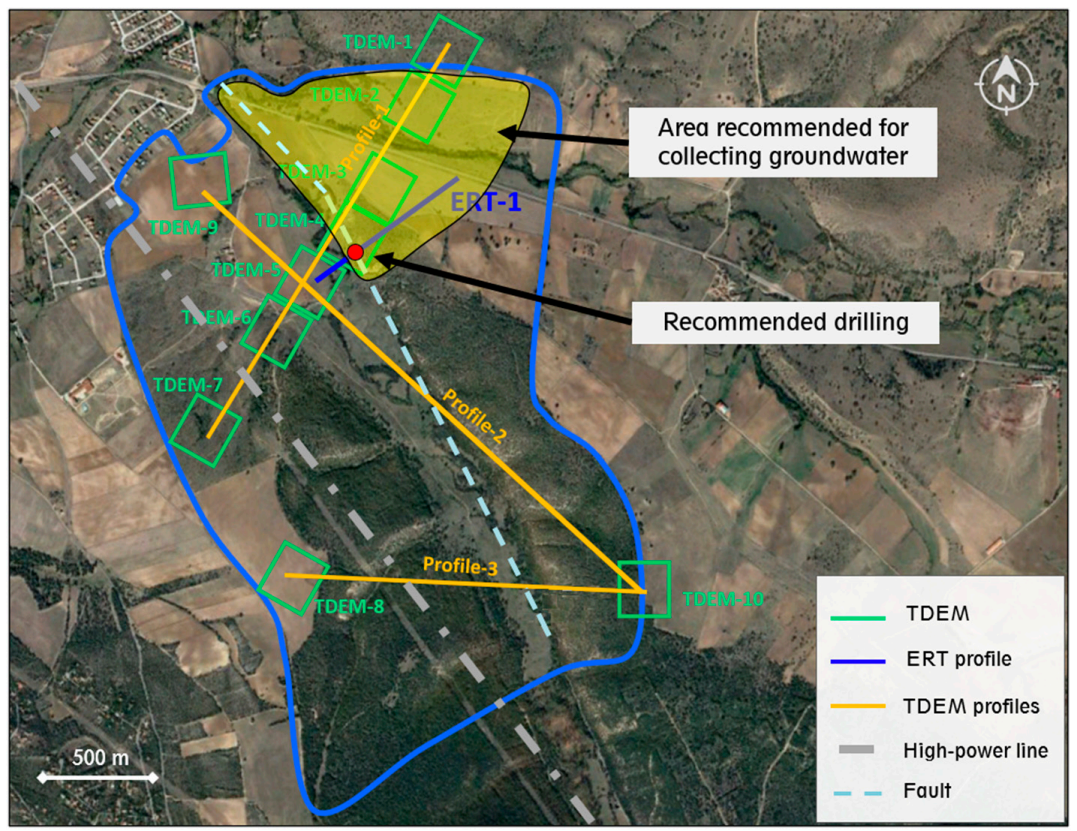

Figure 10. Location of the specific area and drilling recommended for the collection of groundwater.

UTM coordinates of the recommended drilling (previously indicated in Figure 10) are included in Table 4.

Table 4. UTM coordinates (time zone 30T) of the drilling suggested for the exploitation of possible geothermal resources.

\begin{tabular}{ccc}
\hline UTM Coordinates & X & Y \\
\hline Recommended drilling & 446,872 & $4,564,070$ \\
\hline
\end{tabular}

In the end, the existence of geothermal anomalies is judged in this work by three main factors: the existent thermal evidence in the nearby areas, the results of the geophysical prospecting, and the estimation of the geothermal gradient in the area under study. The subsoil materials (known from the geophysics results) are a preliminary indication of the possible geothermal activity. However, this information cannot be used as final evidence. In this way, the existing thermal waters with thermal gradient above the mean value and the estimation of the geothermal gradient in the specific area of study are also useful and necessary to make a global evaluation. It must also be mentioned that the presence of granite formations does not guarantee the existence of geothermal anomalies. Despite this fact, the existence of these materials is favorable for finding geothermal activity.

\subsection{Ground-Source Heat-Pump Uses}

Low-enthalpy geothermal energy can be used at any point of the Earth's crust by the use of heat pumps as ground-source or groundwater heat-pump systems. However, the geological conditions of an area highly influence the global geothermal design and, hence, the final investment of the system.

The site under study is constituted by materials with high thermal conductivities located a few meters from the surface, especially in the south and northwest areas. These geological formations (limestones, dolomites, granites, etc.) make this place an ideal location for the implementation of ground-source heat-pump systems for heating and cooling purposes. 
With the aim of highlighting the importance of the ground characterization to define the specific drilling area, the software GES-CAL [37], designed for the calculation of low-enthalpy geothermal systems, was used in this work. Thus, this tool is useful to compare the differences, in technical and economic terms, between a system placed in the most appropriate area (according to the geophysical results) and in an aleatory one.

Derived from the abovementioned information, Table 5 includes the results of GES-CAL software in the design of three ground-source heat-pump systems in the area under study. Case 1 is planned to be placed in the most favorable conditions in which the granite and gneiss formations are found from the depth $50 \mathrm{~m}$ (profile 3 of Figure 8). Case 2 is, in turn, located in the most extended area where the Paleozoic begins at the depth of $100 \mathrm{~m}$. Finally, Case 3 considers the most unfavorable situation in which the consolidated formations are found from the depth of around $180 \mathrm{~m}$ (Figure 6). When performing the analysis of each assumption with GES-CAL, identical initial conditions are introduced in the software, except for the ground thermal conductivity. In function of the stratigraphic column prevailing in each case, an average value of the ground thermal conductivity was obtained by considering the length of each layer of material and its thermal conductivity from the surface to the depth of $150 \mathrm{~m}$ (common depth of the wells in shallow geothermal systems).

Table 5. Drilling length and initial investment required in the geothermal system of each case, according to the global ground thermal conductivity.

\begin{tabular}{cccc}
\hline Cases & $\begin{array}{c}\text { Ground Thermal } \\
\text { Conductivity } \mathbf{( W / m K )}\end{array}$ & $\begin{array}{c}\text { Total Drilling } \\
\text { Length * }(\mathbf{m})\end{array}$ & Initial Investment $(\boldsymbol{\epsilon})$ \\
\hline Case 1 & 2.178 & 136 & $22,993.38$ \\
Case 2 & 1.920 & 152 & $25,019.23$ \\
Case 3 & 1.286 & 218 & $29,729.28$ \\
\hline \multicolumn{4}{c}{}
\end{tabular}

It is important to mention that the average of the ground thermal conductivity of each case (included in Table 5) was obtained from the officially accepted thermal conductivity values for each material, according to the "Technical Building Code" (CTE) [38].

As can be noted from the results of Table 5, the selection of an appropriate location of the geothermal well field involves significant reductions of the global drilling length required in the system. Additionally, the economic module of GES-CAL allows for the comparison of the initial investment associated to each assumption. Observing Table 5 again, we see Case 1 requires an investment of around $23 \%$ lower than the one required by Case 3 .

Beyond the economic side, it is also important to consider the technical factors that could compromise the performance of the geothermal installation. In this sense, the drilling method selected in the geothermal well field is completely influenced by the geological formations constituting the underground. Reverse circulation methods (associated to loosen materials) are frequently avoided in geothermal systems due to the difficulties of holding the materials during the drilling process without casing. In relation to the cases analyzed in this research, the stratigraphic column of Cases 2 and 3 is mainly constituted by non-consolidated materials (especially in Case 3, in which all the column is made up of this kind of material). This fact would oblige us to use the reverse-circulation technique when carrying out the geothermal wells of these cases, complicating the global process, but also raising the price of the initial investment. Regarding Case 1, the presence of consolidated materials at a more superficial level allows the implementation of rotary percussive drilling techniques. These methods are ideal for the geothermal drilling, because casing is not needed, and the general cost is lower than the reverse-circulation ones. It is important to clarify that GES-CAL does not provide information about the most suitable location of the wells; this location is specifically defined from the geophysical prospecting (distribution of the geological formations in the subsoil). 


\section{Conclusions}

This research has particularly exposed the applicability of the geophysical techniques, TDEM and ERT, in the identification of potential areas for the exploitation of shallow geothermal resources. Geophysical prospecting results have revealed the exact lithology of the ground in the area under study. Based on this knowledge, the following statements were deduced from this work:

- The investigated area is located on the SE edge of the tertiary depression belonging to the Duero Basin. The most superficial geological unities are principally detrital materials: clays, sands, gravels, silts, and sandstones. More in depth, dolomites, limestones, and sandstones are found to finally reach the Paleozoic level (gneiss and granites). Results derived from the implementation of geophysics have allowed us to define the thickness of each layer of materials in the entire area under study.

- Regarding the exploitation of groundwater resources, the highest possibilities of locating thermal waters were detected in the NE side of the study area. More specifically, the fault associated to the Duratón River is considered the most favorable location to exploit the mentioned resource.

- In addition to the possible use of thermal waters, the implementation of ground-source heat-pump systems was analyzed in this research. Even though, in all the area under study, it is possible to install this kind of energy, the information obtained from the geophysical tests has also allowed us to define the most appropriate location of the geothermal well field. The GES-CAL tool was used to compare the design of the shallow geothermal system in different locations of the area. Through this analysis, it has verified that the precise location of the geothermal wells could mean significant economic savings, being also important to avoid possible technical problems during the drilling process.

In conclusion, this research has proved that geophysical prospecting methods, as the ones selected here, constitute a useful tool to firstly define the underground geological characterization, and then to analyze the potential areas for geothermal exploitation. All of this includes the detection of possible thermal water resources, as well as the establishment of the most suitable areas for the location of the well field (in the case of ground-source or groundwater heat-pump systems).

Author Contributions: Conceptualization, C.S.B. and P.C.G.; data curation, I.M.N. and M.Á.M.-G.; formal analysis, C.S.B., P.C.G., and I.M.N.; investigation, C.S.B.; methodology, C.S.B., P.C.G., I.M.N., and M.Á.M.-G.; resources, C.S.B., P.C.G., A.F.M., and D.G.-A.; supervision, A.F.M. and D.G.-A.; validation, C.S.B., P.C.G., I.M.N., M.Á.M.-G., A.F.M., and D.G.-A.; visualization, C.S.B.; writing-original draft, C.S.B. All authors have read and agreed to the published version of the manuscript.

Funding: This research received no external funding.

Acknowledgments: We would like to thank the Department of Cartographic and Land Engineering of the Higher Polytechnic School of Avila, University of Salamanca, for allowing us to use their facilities and for their collaboration during the experimental phase of this research. We also want to thank the University of Salamanca and Santander Bank for providing a pre-doctoral grant (Training of University Teachers Grant) to the corresponding author of this paper; the grant has made possible the realization of the present work.

Conflicts of Interest: The authors declare no conflict of interest.

\section{Appendix A}

This Appendix specifies the technical characteristics of the device used when performing the corresponding geophysical prospecting of this research.

- $\quad$ TDEM equipment

TerraTEM is the device used at the electromagnetic prospecting. It is a new transient electromagnetic survey system that incorporates a $10 \mathrm{Amp}$ transmitter and a true simultaneous $500 \mathrm{kHz}$ three-component receiver. The unit is powered by an external $24 \mathrm{~V}$ battery pack system allowing $6-8 \mathrm{~h}$ of continuous operation. The GPS, which is mounted on the front panel, allows for geolocation information to be automatically recorded with soundings. The user interface comprises a 15" color LCD panel and 
a touchscreen. System parameters are stored automatically with each sounding, for post-survey quality assurance. More information about the specifications of this device are shown in Table A1. Additionally, Figure A1 includes the mentioned device.

Table A1. Specifications of TerraTEM device.

\begin{tabular}{cc}
\hline & TerraTEM \\
\hline Transmitter Output & \\
Receivers & $10 \mathrm{Amps}$. (max.) \\
High-Resolution Sampling Rates & $1 \mathrm{Channel}$ \\
Data Visualization and Processing in Field & $500 \mathrm{kHz}$ \\
Storage Device & Standard Software \\
GPS Receiver & $1 \mathrm{~GB}$ Flash Disk \\
Communications & 12 Channels \\
Extra Stacking Options and Gain Functions & USB and RS-232 Standard \\
Operating Temperature & 10 Selectable Gain Settings from 1 to 8.000 \\
Resolution & $-10-40^{\circ} \mathrm{C}$ \\
Transmitter Current & $23 \mathrm{nV}$ \\
& $50 \mathrm{~A}$ at $6 \mathrm{~V}$ through to $120 \mathrm{~V}(6 \mathrm{~kW})$ \\
\hline
\end{tabular}

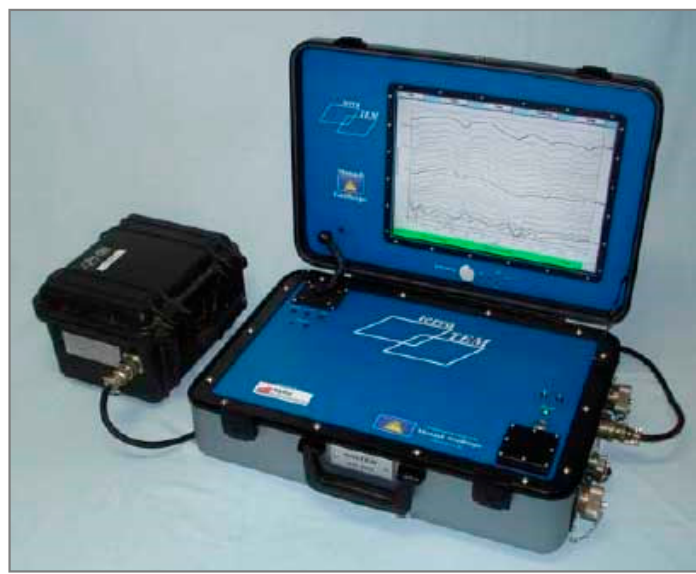

Figure A1. TerraTEM device used in the electromagnetic survey of this research.

- $\quad$ ERT equipment

Regarding the ERT tests, Syscal Pro was the device selected. It is an all-in-one multi-node resistivity and induce polarization sounding and profiling system. Syscal Pro gathers a 10-channels receiver and a $250 \mathrm{~W}$ internal transmitter, making it the more powerful system of the Syscal range. In Figure A2 and Table A2, it is possible to observe the mentioned equipment and its principal specifications.

Table A2. Specifications of Syscal Pro device.

\begin{tabular}{cc}
\hline & Syscal Pro \\
\hline Transmitter max. voltage & $800 \mathrm{~V}$ \\
Transmitter max. current & $2.5 \mathrm{~A}$, accuracy $0.2 \%$ \\
Transmitter max. power & $250 \mathrm{~W}$ \\
Receiver max. voltage & $15 \mathrm{~V}$ \\
Receiver resolution & $1 \mathrm{microV}$ \\
Electrodes & Up to 4000 can be used \\
Data flash memory & More than 21,000 readings \\
Serial link & RS-232 data download \\
Power supply & Two internal rechargeable $12 \mathrm{~V}, 7.2 \mathrm{Ah}$ \\
Casing & Optional external $12 \mathrm{~V}$ batteries \\
Operating Temperature & Shock resistant fiber-glass case \\
\hline
\end{tabular}




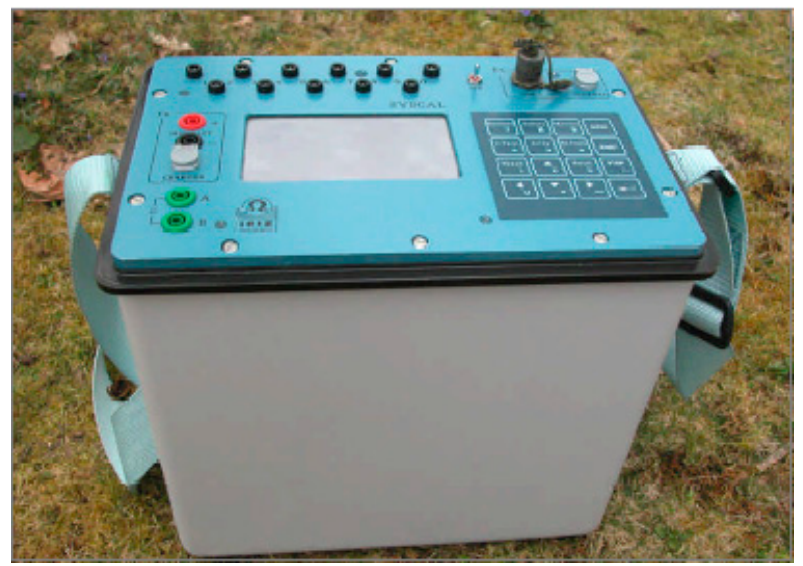

Figure A2. Syscal Pro device used when carrying out the 2D electrical resistivity tomography of this research.

\section{Appendix B}

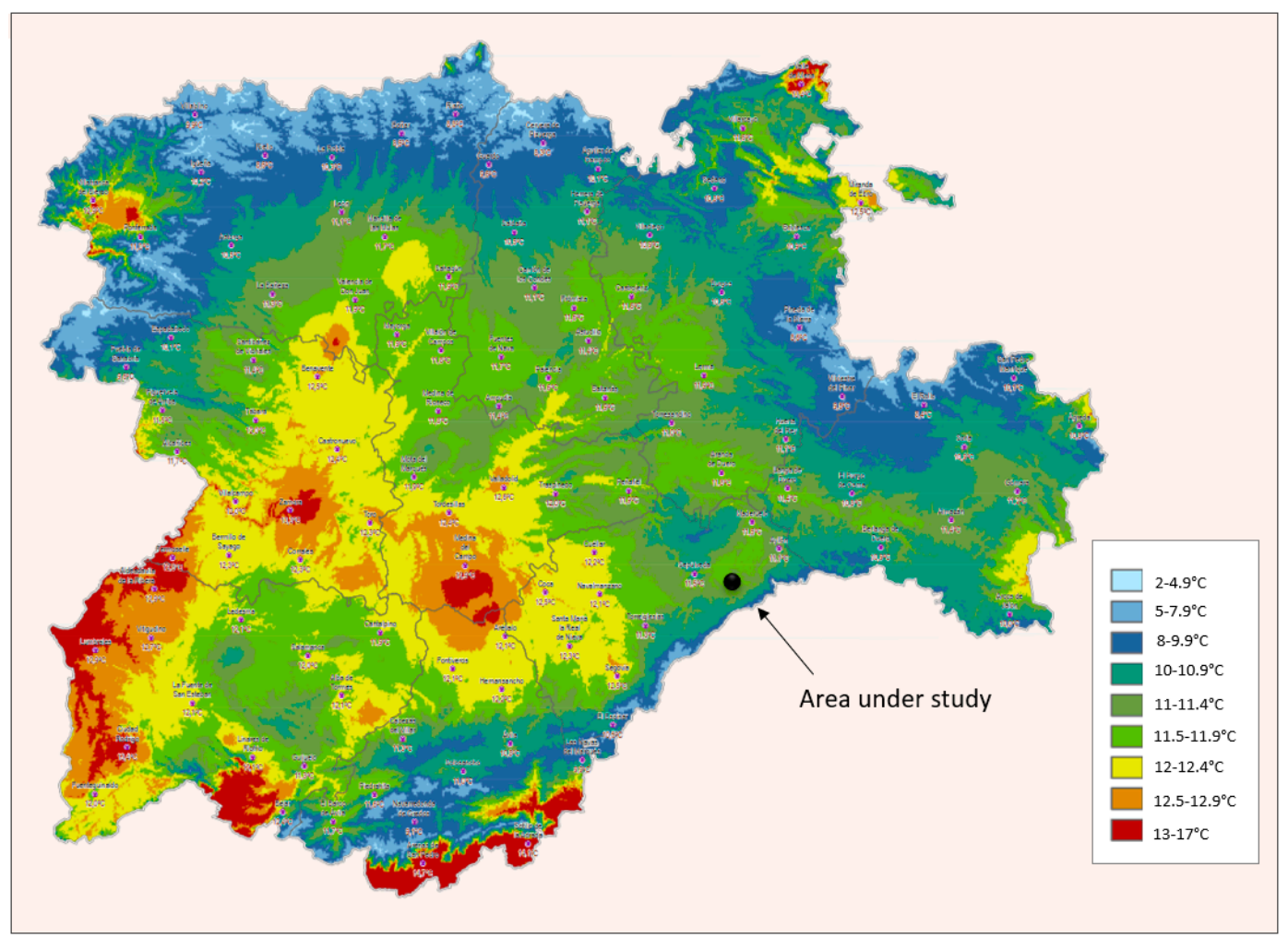

Figure A3. Average annual temperature in the area considered in this research for the period 1981-2010 [39].

\section{References}

1. Armstead, H.C. Geothermal Energy: Its Past, Present and Future Contribution to the Energy Needs of Man, 2nd ed.; E. \& F.N Spon: New York, NY, USA; London, UK, 1983.

2. Bodvarsson, G. Evaluation of geothermal prospects and the objectives of geo-thermal exploration. Geoexploration 1970, 8, 7-17. [CrossRef]

3. Sena-Lozoya, E.B.; González-Escobar, M.; Gómez-Arias, E.; González-Fernández, A.; Gómez-Ávila, M. Seismic exploration survey northeast of the Tres Virgenes Geothermal Field, Baja California Sur, Mexico: A new Geothermal prospect. Geothermics 2020, 84, 101743. [CrossRef] 
4. Kearey, P.; Brooks, M.; Hill, I. An Introduction to Geophysical Exploration; John Wiley \& Sons: Hoboken, NJ, USA, 2013.

5. Aretouyap, Z.; Nouck, P.N.; Nouayou, R. A discussion of major geophysical methods used for geothermal exploration in Africa. Renew. Sustain. Energy Rev. 2016, 58, 775-781. [CrossRef]

6. Mariita, N.O. Strengths and weaknesses of gravity and magnetics as exploration tools for geothermal energy. In Proceedings of the Short Course V on Exploration for Geothermal Resources, Naivasha, Kenya, 29 Octomber-19 November 2010.

7. DomraKana, J.; Djongyang, N.; Raïdandi, D.; Nouck, P.N.; Dadjé, A. A review of geophysical methods for geothermal exploration. Renew. Sustain. Energy Rev. 2015, 44, 87-95. [CrossRef]

8. Bibby, H.M.; Risk, G.F.; Caldwell, T.G.; Bennie, S.L. Misinterpretation of electrical resistivity data in geothermal prospecting: A case study from the Taupo Volcanic Zone. In Geological and Nuclear Sciences, Proceedings of the World Geothermal Congress; World Geothermal Congress: Antalya, Turkey, 2005; pp. 1-8.

9. Deckert, H.; Bauer, W.; Abe, S.; Horowitz, F.G.; Schneider, U. Geophysical greenfield exploration in the permo-carboniferous Saar-Nahe basin-The Wiesbaden Geothermal Project, Germany. Geophys. Prospect. 2018, 66, 144-160. [CrossRef]

10. Subasinghe, N.D.; Nimalsiri, T.B.; Suriyaarachchi, N.B.; Hobbs, B.; Fonseka, M.; Dissanayake, C. Study of Thermal Water Resources in Sri Lanka Using Time Domain Electromagnetics (TDEM). En Advanced Materials Research; Trans Tech Publications Ltd.: Freienbach, Switzerland, 2014; pp. 3198-3201.

11. Fadillah, T.; Sulistijo, B.; Notosiswoyo, S.; Kristanto, A.; Yushantarti, A. The Resistivity Structure of Aluvial in Geothermal Prospect. Using Time Domain Electromagnetic Methode (TDEM) Survey. In Proceedings of the World Geothermal Congress 2015, Melbourne, Australia, 19-25 April 2015.

12. Sáez Blázquez, C.; Martín, A.F.; García, P.C.; González-Aguilera, D. Thermal conductivity characterization of three geological formations by the implementation of geophysical methods. Geothermics 2018, 72, 101-111. [CrossRef]

13. Martín Nieto, I.; Farfán Martín, A.; Sáez Blázquez, C.; González-Aguilera, D.; Carrasco García, P.; Farfán Vasco, E.; Carrasco García, J. Use of 3D electrical resistivity tomography to improve the design of low enthalpy geothermal systems. Geothermics 2019, 79, 1-13. [CrossRef]

14. Bibby, H.M.; Dawson, G.B.; Rayner, H.H.; Bennie, S.L.; Bromley, C.J. Electrical resistivity and magnetic investigations of the geothermal systems in the Rotorua area, New Zealand. Geothermics 1992, 21, $43-64$. [CrossRef]

15. Tang, X.; Zhang, J.; Pang, Z.; Hu, S.; Tian, J.; Bao, S. The eastern Tibetan Plateau geothermal belt, western China: Geology, geophysics, genesis, and hydrothermal system. Tectonophysics 2017, 717, 433-448. [CrossRef]

16. Abubakar, A.J.A.; Hashim, M.; Pour, A.B. Remote sensing satellite imagery for prospecting geothermal systems in an aseismic geologic setting: Yankari Park, Nigeria. Int. J. Appl. Earth Obs. Geoinf. 2019, 80, 157-172. [CrossRef]

17. Arzate, J.; Corbo-Camargo, F.; Carrasco-Núñez, G.; Hernández, J.; Yutsis, V. The Los Humeros (Mexico) geothermal field model deduced from new geophysical and geological data. Geothermics 2018, 71, $200-211$. [CrossRef]

18. Long, C.L.; Kaufmann, H.E. Reconnaissance geophysics of a known geothermal resource area, Weiser, Idaho and Vale, Oregon. Geophysics 1980, 45, 312-322. [CrossRef]

19. Volpi, G.; Manzella, A.; Fiordelisi, A. Investigation of geothermal structures by magnetotellurics (MT): An example from the Mt. Amiata area, Italy. Geothermics 2003, 32, 131-145. [CrossRef]

20. Hermans, T.; Vandenbohede, A.; Lebbe, L.; Nguyen, A. shallow geothermal experiment in a sandy aquifer monitored using electric resistivity tomography. Geophysics 2012, 77, 11-21. [CrossRef]

21. Magna 50. Mapa Geológico de España 1:50.000; Instituto Geológico y Minero de España: Sepúlveda, Spain, 2003; hoja 431.

22. Aguas Minerales y Termales de España. IGME, Instituto Geológico y Minero de España. Available online: http://aguasmineralesytermales.igme.es/inicio.aspx (accessed on 1 January 2020).

23. Hapsoro, C.A.; Srigutomo, W.; Purqon, A. 3-D Modeling of Layered Earth Structure in the Geothermal Systems Using Time Domain Electromagnetics (TDEM) Method. IOP Conference Series: Earth and Environmental Science; IOP Publishing: Bristol, UK, 2019; Volume 318.

24. Goldman, M.; Rabinovich, B.; Rabinovich, M.; Gilad, D.; Gev, I.; Schirov, M. Application of the integrated NMR-TDEM method in groundwater exploration in Israel. J. Appl. Geophys. 1994, 31, 27-52. [CrossRef] 
25. Descloitres, M.; Chalikakis, K.; Legchenko, A.; Moussa, A.M.; Genthon, P.; Favreau, G.; Le Coz, M.; Boucher, M.; Oï, M. Investigation of groundwater resources in the Komadugu Yobe Valley (Lake Chad Basin, Niger) using MRS and TDEM methods. J. Afr. Earth Sci. 2013, 87, 71-85. [CrossRef]

26. Fitterman, D.V.; Stewart, M.T. Transient Electromagnetic Sounding for Groundwater. Geophysics 1986, 51, 889-1033. [CrossRef]

27. Kumar, D.; Thiagarajan, S.; Rai, S.N. Deciphering geothermal resources in Deccan Trap region using electrical resistivity tomography technique. J. Geol. Soc. India 2011, 78, 541-548. [CrossRef]

28. Carrier, A.; Lupi, M.; Fishanger, F.; Nawratil de Bono, C. Deep-reaching electrical resistivity tomography (ERT) methods for middle-enthalpy geothermal prospection in the Geneva Basin, Switzerland. In Proceedings of the EGU General Assembly Conference Abstracts, Vienna, Austria, 8-13 April 2018; p. 20.

29. Chabaane, A.; Redhaounia, B.; Gabtni, H. Combined application of vertical electrical sounding and 2D electrical resistivity imaging for geothermal groundwater characterization: Hammam Sayala hot spring case study (NW Tunisia). J. Afr. Earth Sci. 2017, 134, 292-298. [CrossRef]

30. Maté-González, M.Á.; Sánchez-Aparicio, L.J.; Sáez Blázquez, C.; Carrasco García, P.; Álvarez-Alonso, D.; de Andrés-Herrero, M.; García-Davalillo, J.C.; González-Aguilera, D.; Herández Ruiz, M.; Jordá Bordehore, L.; et al. On the Combination of Remote Sensing and Geophysical Methods for the Digitalization of the San Lázaro Middle Paleolithic Rock Shelter (Segovia, Central Iberia, Spain). Remote Sens. 2019, 11, 2035. [CrossRef]

31. Daniels, F.; Alberty, R.A. Physical Chemistry; Mir: Moscow, Russia, 1966; p. 291.

32. Mainoo, P.A.; Manu, E.; Yidana, S.M.; Agyekum, W.A.; Stigter, T.; Duah, A.A.; Preko, K. Application of 2D-Electrical resistivity tomography in delineating groundwater potential zones: Case study from the voltaian super group of Ghana. J. Afr. Earth Sci. 2019, 160, 103618. [CrossRef]

33. Zhou, B.; Moosoo, W. Multi-Parameter Tomographic Inversion for Imaging 2D Electrical Resistivity Anisotropy. 1st Conference on Geophysics for Geothermal-Energy Utilization and Renewable-Energy Storage. Eur. Assoc. Geosci. Eng. 2019, 1,1-5.

34. deGroot-Hedlin, C.; Constable, S. Occam's inversion to generate smooth, two-dimensional models from magnetotelluric data. Geophysics 1990, 55, 1613-1624. [CrossRef]

35. Rajesh, R.; Tiwari, R.K. FORTRAN code to convert resistivity Vertical Electrical Sounding data to RES2DINV format. Site Characterisation Using Multi-Channel Anal. Surf. Waves Var. Locat. Kumaon Himalayas India 2018, 22, 359-363.

36. Istiqomah, A.N. Analisis Komparasi Inversi Software Res2Dinv dan Ipi2Win Pada Metode Vertical Electrical Sounding (VES); SKRIPSI Mahasiswa UM: Kuala Lumpur, Malaysia, 2019.

37. Sáez Blázquez, C.; Martín Nieto, I.; Mora, R.; Farfán Martín, A.; González-Aguilera, D. GES-CAL: A new computer program for the design of closed-loop geothermal energy systems. Geothermics 2020, 87, 101852. [CrossRef]

38. Structural solutions file. In Technical Building Code, CTE; Institute of Structural Sciences of Eduardo Torroja and Structural Institute of Castilla y León: Castilla y León, Spain, 2007.

39. Agencia Estatal de Meteorología (AEMET). Series of Annual Average Temperatures of AEMET Stations (Spain). Observations of the Thirty-Year Period 1981-2010, Completed, Refined and Homogenized; Agencia Estatal de Meteorología (AEMET): Madrid, Spain, 2010.

(C) 2020 by the authors. Licensee MDPI, Basel, Switzerland. This article is an open access article distributed under the terms and conditions of the Creative Commons Attribution (CC BY) license (http://creativecommons.org/licenses/by/4.0/). 